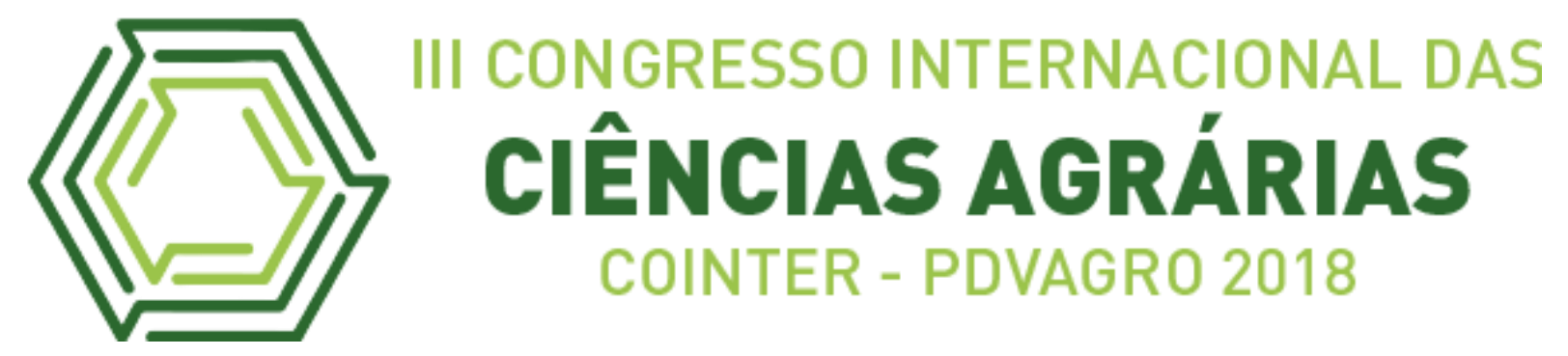

\title{
TOLERÂNCIA DE BACTÉRIAS DO GÊNERO BACILLUS ADIFERENTES CONCENTRAÇÕES DO INSETCIDA METOMIL
}

\section{TOLERANCE OF BACTERIA OF THE GENUS BACILLUS TO DIFFERENT CONCENTRATION OF THE METHOMYL PESTICIDE}

\author{
Apresentação: Pôster
}

\begin{abstract}
Alyson da Silva Amorim ${ }^{1}$;José Maciel Mariano da Silva ${ }^{2}$;Anderson Silva de Carvalho ${ }^{3}$;
\end{abstract} Everlaine Leopoldino Dias Silva ${ }^{4}$;úlia Kuklinsky Sobral ${ }^{5}$

DOI: https://doi.org/10.31692/2526-7701.IIICOINTERPDVAGRO.2018.00678

\section{Introdução}

A aplicação de bactérias em sistemas agrícolas e ambientais está sendo explorado em diversos aspectos, inclusive visando a biorremediação ambiental, visto que muitas bactérias são versáteis quanto a tolerância e até biodegradação de compostos químicos, como os resíduos dos pesticidas que contaminam os solos agrícolas.Dentre tais bactérias, o gênero Bacillus se destaca por apresentar a capacidade de crescer em variados ambientes, possuindo

\footnotetext{
${ }^{1}$ Engenharia Agronômica, Universidade Federal Rural de Pernambuco, alysonamorim.ccb@hotmail.com

${ }^{2}$ Engenharia Agronômica, Universidade Federal Rural de Pernambuco, jmaciel_mariano@outlook.com

${ }^{3}$ Engenharia Agronômica, Universidade Federal Rural de Pernambuco, anderson_carvalho18@hotmail.com

${ }^{4}$ Engenharia Agronômica, Universidade Federal Rural de Pernambuco, everlaineldias@gmail.com

${ }^{5}$ Professor Associado na UFRPE-UAG,Universidade Federal Rural de Pernambuco, jksobral@yahoo.com.br
} 
habilidade de conservar o meio ambiente, através de sua habilidade em biodegradar compostos poluentes (PEREIRA et al., 2012).

Diante disso, o objetivo do presente trabalho foi avaliar a tolerância a diferentes concentrações do inseticida metomil, utilizado no controle da Spodoptera frugiperda, praga chave da cultura do milho, por bactérias do gênero Bacillus.Para o teste de tolerância ao inseticida metomil, foram avaliadas duas linhagens bacterianas pertencentes ao gênero Bacillus(UAGAT35 e UAGAT71).Foi utilizado o meio mínimo mineral líquido modificado acrescido de glicose, onde cada tratamento recebeu 25,50, 100 e $200 \mathrm{mg} \mathrm{L}^{-1}$ do inseticida metomil, além do tratamento controle, isento de inseticida.As duas bactérias avaliadas apresentaram tolerância ao inseticida, pois ambas desenvolveram-se bem em diferentes concentrações do metomil, sendo assim, aptas para exploração em programadas de manejo integrado, inclusive para avaliações visando a biorremediação ambiental.

\section{Fundamentação Teórica}

Uma das principais pragas do milho é pertencente à ordem Lepidoptera, da família Noctuidade, a espécie Spodopterafrugiperda ( J. E. Smith ), conhecida vulgarmente como a lagarta do cartucho (FERNANDES ET AL., 2014). O inseto ataca a parte aérea, onde após a eclosão dos ovos, as lagartas, efetuam raspagem nas folhas (ROSA, 2011), e conforme os insetos vão crescendo fazem perfurações nas folhas, penetrando o cartucho, podendo danificar as espigas da cultura (MAPA, 2003).

Dentre os insumos agrícolas usados na produção agrícola do milho está o metomil, pesticida usado no controle da S.frugiperda, o mesmo faz parte do grupo químico metilcarbamato de oxima, que atua na transmissão sináptica inibindo a enzima acetilcolinesterase, ou seja, não permite a catalisação do neurotransmissor acetilcolina através 
de sua enzima, provocando assim a passagem contínua dos impulsos nervosos, levando o inseto à fadiga e, consequentemente, a morte ( GALLO et al., 2002).Embora tenha o manejo integrado de pragas (MIP) ainda é comum usar inseticidas químicosna agricultura, objetivando maior praticidade e eficiência no controle da Spodopterafrugiperda. Existem vários inseticidas registrados pelo Ministério da Agricultura, Pecuária e Abastecimento (2003) , como por exemplo estão os organofosforados, espinosinas, metilcarbamatos e entre outros e por conta do mal uso destes xenobióticos é bem visível a contaminação de solos,fontes hídricas, rios, lagos etc.Com isso, o uso da biodegradação de pesticidas por bactérias é importante e muito explorada nos estudos relacionados à biorremediação ambiental ( JOUTEY ET AL,. 2013 ). Há hoje uma preocupação em desenvolver técnicas que venhamminimizar os impactos causados pelas más práticas agrícolas.Atualmente, o uso de bactérias promotoras de crescimento em plantas (BPCP) também está sendo uma alternativa muito vantajosa na agricultura, pois além do interesse em conduzir uma produção econômica e de alta qualidade, são usados como critérios de preservação ambiental e saúde humana (DARTORA et al., 2013).

Esse grupo de bactérias se classifica como micro-organismos benéficos, que podem estar localizados endofiticamente (no interior) ou epifíticamente (na superfície) nos vegetais (COMPANT; CLÉMENT; SESSITSCH, GARCIA et al 2002). É interessante ressaltar que todas estas e outras características executadas por esse grupo de micro-organismos, dependem de uma relação íntima e direta entre genótipos da bactéria interagindo com genótipo da planta ( KUKLINSKY-SOBRAL et al., 2004). O uso de BPCPvem sendo estudado quanto a biorremediação ambiental, visto que muitos dos solos agrícolas estão contaminados por xenobióticos nocivos ao meio ambiente, como por exemplo os pesticidas.Dentre tais bactérias,está o gêneroBacillus, que possuem capacidade de sobreviver em condições adversar, como a presença de xenobióticos e ainda expressarem características como a promoção de crescimento vegetal, além disso,possuem habilidade de preservar o meio ambiente usandoos xenobióticos como fonte de carbono, biodegradando as substâncias poluentes. Sendo assim, o objetivo do presente trabalho foi avaliar a tolerância de duas linhagens deBacillus, UAGAT35 e UAGAT71,em relação a diferentes concetrações do inseticida metomil, utilizado no controle da S. frugiperda. 


\section{Metodologia}

Foram utilizadas duas linhagens bacterianas deBacillussp., UAGAT35 e UAGAT71 (SILVA et al., 2016), as mesmas foram mantidas em meio TSA ( TripcaseSoy Agar ) e sob refrigeração de $4{ }^{\circ} \mathrm{C}$, no laboratório de Genética e Biotecnologia Microbiana (LGBM) da Unidade Acadêmica de Garanhuns da Universidade Federal Rural de Pernambuco (UAG - UFRPE).Para a avaliação de tolerância ao metomil, foi avaliado um inseticida comercial utilizado no controle da Spodoptera frugiperda em milho, o Lannate BR, que tem o Metomil como ingrediente ativo (215 g.i.a L), fabricante Du Pont.

As bactérias foram inoculadas a partir de colônias isoladas em meio TSA (TrypcaseSoyAga) 10\% líquido, sendo mantidas sob agitação constante (125 rpm), durante 24-48 horas.Após, retirou-se $2 \mathrm{~mL}$ do inóculo para a verificação da densidade óptica em espectrofotômetro $(600 \mathrm{~nm})$, sendo transferidos 10 microlitros do inóculo bacteriano para tubos contendo $25 \mathrm{~mL}$ de Meio Mínimo Mineral (MMM) líquido modificado: $3 \mathrm{~g} \mathrm{~K}_{2} \mathrm{HPO}_{4}$;

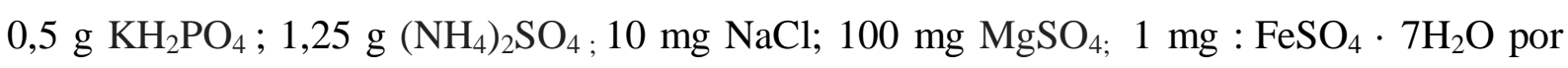
litro, com PH 7,3 ( MENDONZA et AL. , 2011 ), acrescido de glicose ( 10 g. ${ }^{1)}$ como fonte de carbono, seguido dos seguintes tratamentos: $0 \mathrm{mg} \mathrm{L}{ }^{-1}-25 \mathrm{mg} \mathrm{L}^{-1}-50 \mathrm{mgL}^{-1}-100 \mathrm{mgL}^{-1}-$ $200 \mathrm{mgL}^{1}$ do inseticida Metonil. Em seguida,as amostras foram inoculadas sob agitação constante $(124 \mathrm{rpm})$, à $28^{\circ} \mathrm{C}$. Durante 11 dias, a densidade Óptica foi verificada em seis leituras, em intervalos de 24 horas para as cinco primeiras leituras e um intervalo final de 6 dias para a última leitura. $\mathrm{O}$ experimento foi realizado em triplicata, foi aplicada a análise de variância (ANOVA) e as médias comparadas pelo teste de Scott-Knott a 5\% de probabilidade, utilizando o programa estatístico SISVAR versão 5.4 (FERREIRA, 2010).

\section{Resultados e Discussões}


Gráfico 1: Densidade Óptica (600 nm) das Bactérias UAGAT 35 E UAGAT 71 em Meio de Cultura MMM Acrescido de Glicose Sob os Tratamentos de Diferentes Concentrações do Inseticida Metomil Durante 11 Dias

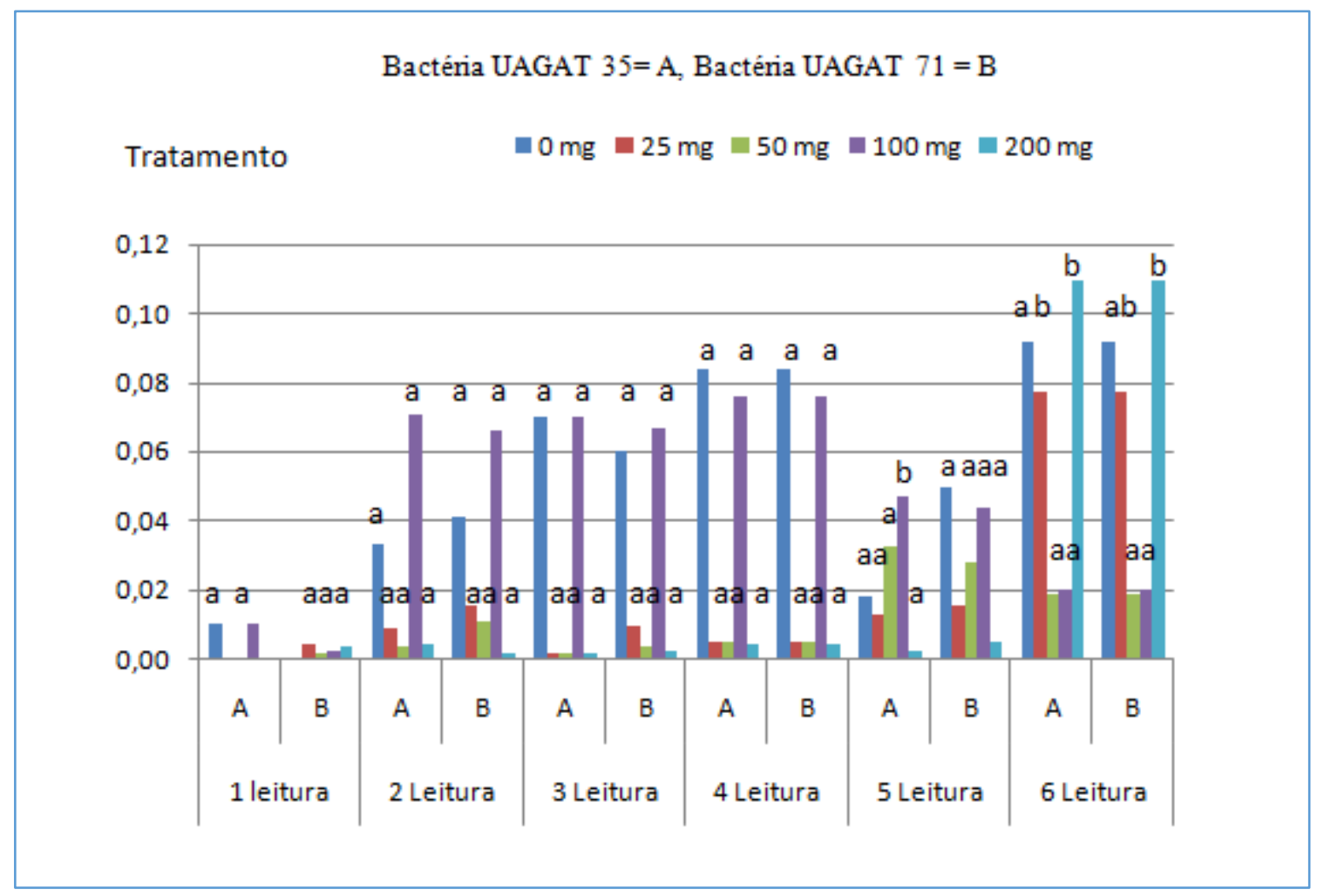

Não houve diferença estatística entre as bactérias nos diferentes tratamentos. Entre a quinta e a sexta leitura houve um intervalo de 6 dias, com isso percebeu-se que em ambas as bactérias submetidas ao tratamento de $200 \mathrm{mgL}^{1}$ apresentaram maior crescimento bacteriano, podendo-se especular que no decorrer dos dias, as mesmas foram adquirindo tolerância a esta 
concentração,este mesmo efeito ocorreu ao tratamento de $25 \mathrm{mgL}^{-1}$. Em relação ao tratamento $100 \mathrm{mgL}^{1}{ }^{1}$ até a quarta leitura as bactérias apresentaram boa tolerância,todavia ao passar da quarta até a sexta leitura ocorreu um decréscimo de tolerância em ambas bactérias, sendo refletido por sua queda no crescimento bacteriano. Em relação ao desdobramento tempo e tratamento na análise estatística, a bactéria UAGAT35 e 71, nos tratamentos $25 \mathrm{mgL}^{-1}$ e 200 $\mathrm{mgL}^{1}$ na quinta e sexta leitura, apresentou um melhor desenvolvimento e tolerância quando comparada as leituras anteriores, mas estatisticamente não houve diferença entre elas. E em relação ao desdobramento das bactérias aos tratamentos não houve diferença estatísticas entre elas..

\section{Conclusões}

As bactérias UAGAT35 e UAGAT71, do gênero Bacillus, foram capazes de crescer em diferentes concentrações do inseticida metomil, ou seja, apresentaram tolerância até concentrações maiores que a aplicação no campo.Com isso, as mesmas podem ser usadas melhor exploradas em programas de manejo integrado, visando até a capacidade de biorremediação de inseticidas.

\section{Referências}

AGROFIT: Ministério da Agricultura Pecuária e Abastecimento.2003.Acessado em 17 de set. 2018. Disponível em: http:extranet.agricultura.gov.br-agrofit .

BATISSON, I; CROUZET, O; BESSE-HOGGAN, P; SANCELME, M; MANGOT, JF; MALLET, C; BOHATIER, J. Isolamento e Caracterização de Bacillussp. do Solo. Editado por Bernd NowackVolume 157, Edição 4, Páginas 1063-1396 (abril de 2009). 
CONAB: Companhia Nacional de Abastecimento. 2018. 2003. Acessado em 17 de set. 2018. Disponível em: https://www.conab.gov.br/ultimas-noticias/2359-safra-de-graos-volta-anivel-historico-com-producao-de-232-milhoes-de-toneladas.

FERREIRA, D.F SISVAR- Sistema de análise de variância. Versão 5.4 UFLA- MG Lavras, 2010.

FERNANDES, O.D.; PARRA, J.R.; NETO, A.F.; PÍCOLI, R.; BORGATTO, A.F .e DEMÉTRIO, C.G.B. Efeito do milho geneticamente modificado MON810 sobre a lagarta-do-cartucho Spodopterafrugiperdp (J.E.Smith, 1797) (Lepidoptera: Noctuidae). Revista Brasileira de Milho e Sorgo. V.2, n.2. 25-35 p. Piracicaba. 2003.

GALLO, D.; NAKANO, O.; SILVEIRA NETO, S.; CARVALHO, R. P. L.; BATISTA, G. C.; BERTI FILHO, E.; PARRA, J. R. P.; ZUCCHI, R. A.; ALVES, S.B.; VENDRAMIN, J. D.; MARChINI, L. C.; LOPES, J. R. S.; OMOTO, C. Entomologia Agrícola. 920 p. FEALQ.Piracicaba, 2002.

JIN-LIANG, XU; JUN, WU; ZHI-CHUN, WANG; KUN, WANG; MENG-YING, LI; JIANDONG, JIANG; JIAN, HE e SHUN-PENG, LI. Isolation and Characterization of a Methomyl-Degrading Paracoccus sp. Mdw-1. Pedosphere. 238-243 p.china, 2009.

MENDOZA, JOSÉ C.; PEREA, YAZMIN S.; SALVADOR, JAME A.; MORALES, JANETTE A. e PÉREZ, GABRIELA. Biodegradación Bacteriana de PlaguicidasPermetrina Y Cipermetrina em Cultivo Lote. Avances em Ciencias e ingeniería, vol. 2, n.3. 45-55 p. Puebla, México. 2011.

MENEZES, ANASTÁCIO F.; OKEKE, THOMAS W.Biorremediação de Solos Contaminados por óleo Diesel. Braz. J. Microbiol. vol.34 suppl.1 São Paulo Nov. 2003

NITSCHKE, M.; PASTORE, GM. Biossurfactantes: Propriedades e Aplicações.Quim. Nova, Vol. 25, No. 5, 772-776, 2002.,Capinas-SP, 2002.

PEREIRA, A,R; FREITA, D.A. Uso de Microorganismos Para a Biorremediação de 
Ambientes Impactados. Rev. Elet. em Gestão, Educação e Tecnologia Ambiental. v(6), $\mathrm{n}^{\circ}$ 6, p. $975-1006,2012$.

SENE,L.; CONVERTI, A.; SECCHI, G.A.R; SIMAO, R.C.G. New aspectsonatrazinebiodegradation. Braz. Arch. Biol. Technol. 2010, vol.53, n.2.

SILVA, G.F; SANTOS, I.B; SOUSA, A.J; FARIAS, A.R; DINIZ, P.W; SOBRAL, K.S; FREIRE, M.B. Bioprospecting and plant growth-promoting bacteria tolerant to salinity associated with Atriplex nummularia L. in saline soils. African Journal of Microbiology Research. Vol. 10(31), pp. 1203-1214, 21 August, 2016.

VARGHA, M., TAKATS, Z., MARIALIGETI K. (2005). Degradação da atrazina em um sistema modelo em escala de laboratório com o rio Danúbio sedimentos. Wat. Res., 39 , $1560-1568$. 